\title{
Treatment of lower urinary tract symptoms in multiple sclerosis patients: Review of the literature and current guidelines
}

\author{
Shachar Moshe Aharony, MD; Ornella Lam, MD; Jacques Corcos, MD² \\ 'Urology Service, Rabin Medical Centre, Beilinson Hospital, Pteach-Tiqva, Israel; 2Department of Urology, Jewish General Hospital, McGill University, Montreal, QC, Canada
}

Cite as: Can Urol Assoc J 2017;11 (3-4):E1 10-5. http://dx.doi.org/10.5489/cuaj.4059

Published online March 16, 2017

This is a followup to the review entitled, "Evaluation of lower urinary tract symptoms in multiple sclerosis patients," published in the February 2017 issue of CUAJ.

\section{Abstract}

Multiple sclerosis (MS) is a unique neurological disease with a broad spectrum of clinical presentations that are time- and disease course-related. Lower urinary tract symptoms (LUTS) are highly prevalent in this patient population, with approximately $90 \%$ showing some degree of voiding dysfunction and/or incontinence 6-8 years after the initial MS diagnosis. Major therapeutic goals include quality of life improvement and the avoidance of urological complications

Owing to the wide divergence of clinical symptoms and disease course, evaluation and treatment differ between patients. Treatment must be customized for each patient based on disease phase, patient independence, manual dexterity, social support, and other medical- or MS-related issues. Ablative or irreversible therapies are indicated only when the disease course is stable. In most cases of "safe" bladder, behavioural treatment is considered first-line defense. Antimuscarinic drugs, alone or in combination with intermittent self-catheterization, are currently the mainstay of conservative treatment, and several other medications may help in specific disease conditions. Second-line treatment includes botulinum toxin A injection, neuromodulation, indwelling catheters, and surgery in well-selected cases.

\section{Introduction}

Multiple sclerosis (MS) is a unique neurological disease with a broad spectrum of clinical presentations that are time- and disease course-related. Due to the divergence of patients' symptoms, urologists must have a thorough knowledge of the MS disease process (as we have discussed in a prior article ${ }^{1}$ ) to correctly evaluate and manage MS-related lower urinary tract symptoms (LUTS). When making clinical decisions, adjustments should be accommodated according to patient mobility, disease phase, manual dexterity, social support, comorbidities, and MS-related urinary symptoms. MS-related LUTS treatment focuses on improving quality of life (QOL) by reducing incontinence and ameliorating storage symptoms and bladder emptying, while avoiding urological complication, such as urinary tract infections (UTIs), bladder and kidney stones, hydronephrosis, and renal function deterioration. Patients should be divided into high- or low-risk for renal function deterioration. Those with indwelling catheters and elevated detrusor storage pressure are at high risk. These factors elicit upper urinary tract (UUT) problems in up to $10 \%$ of patients, usually $6-8$ years after urinary symptom manifestation. ${ }^{2}$ Some authors suggest that the true incidence of UUT deterioration is as low as $0.34 \%$. $^{3}$

\section{Behavioural/physical treatment}

Patients with only mild disability and symptoms of overactive bladder $(\mathrm{OAB})$ may benefit from pelvic floor muscle training (PFMT). ${ }^{4}$ Such training is helpful only among patients with intact neural pathways to the pelvic floor, who are able to contract it. This kind of treatment is suspected to enhance the inhibitory effect of pelvic floor contraction on the detrusor muscle. ${ }^{5}$ Several authors have demonstrated the positive influence of PFMT on disease course. ${ }^{6-9}$ However, it is difficult to make general treatment recommendations based on these reports, as they only discuss low-volume, gender-specific methods of outcome assessment. For now, behavioural treatment is indicated only in a minority of patients with mild disability, OAB symptoms, and intact neural pathways to the pelvic floor. Further research is needed to evaluate the effectiveness of such interventions.

Emptying problems are harder to manage with conservative treatment. Timely voiding or double voiding will allow proper emptying without necessitating other interventions, but only in a small group of well-selected patients. ${ }^{10}$ 


\section{Pharmacotherapy}

\section{Treatment of impaired storage}

Antimuscarinic drugs, alone or sometimes in combination with intermittent catheterization (IC), are currently the first-line medical treatment in neurogenic LUTS (Level of evidence: $1 \mathrm{~A}) .{ }^{11-15}$ When giving anticholinergics without IC, post-void residual (PVR) volume must be monitored before and during the treatment period. Most data on the efficacy and adverse effects of these drugs derive from idiopathic detrusor overactivity (IDO) patients. Only a few trials have investigated neurogenic detrusor overactivity (NDO) patients, and data on MS cases are scarce.

In a meta-analysis by Nicholas et al, the authors could not advocate the use of anticholinergics in MS. ${ }^{16}$ Ethans et al observed that tolterodine was effective in a group of 48 NDO patients, 10 of whom suffered from MS. ${ }^{17}$ Tolterodine $2 \mathrm{mg}$ twice daily was significantly superior to placebo in enhancing catheterization volume and reducing the number of incontinence events. Its efficacy was comparable to that of oxybutynin, with significantly improved side effect profile (dry mouth).

Recently, van Rey and Heesakkers described the beneficial impact of solifenacin on urinary urgency incontinence (UUI) events and symptomatic improvement in 30 MS patients. ${ }^{18} \mathrm{UUI}$ episodes/24 hours decreased from 1.3 to 0.2 , number of pads per day dropped from 2.0 to 1.0 , frequency/day diminished to 9.5 from 11.7, and micturition volume rose from 121.9 to $155.3 \mathrm{cc}$.

As in other NDO patients, Bennett et al demonstrated oxybutynin dose-escalation tolerability in a combined neurogenic population, including MS patients (22 out of 39). ${ }^{19}$ High oxybutynin doses (up to $30 \mathrm{mg}$ ) engendered statistically significant decreases in the number of voids in 24 hours, nocturia, and incontinence episodes. Oxybutynin doses higher than $15 \mathrm{mg}$ were requested by $74.4 \%$ of patients at the end of the study. No patient experienced serious adverse events and none dropped out during the 12-week course, although previous work has raised concerns about the cognitive effect of oxybutynin in populations with potential cognitive impairment. ${ }^{20}$ Albeit anticholinergics administration in MS is not supported by strong evidence, they still remain the most prevalent first-line treatment for $O A B$ symptoms. Oxybutynin, trospium, tolterodine, and propiverine are all well-established (Level of evidence: $1 \mathrm{~A}),{ }^{13}$ efficient, long-term treatment options in NDO. Recent data from MS patients support the prescription of darifenacin and solifenacin with similar effectiveness and favourable adverse event profile.

Desmopressin is widely administered to address nocturnal polyuria in both men and women. ${ }^{21,22}$ The data on MS patients are limited, not up-to-date, and not gender-specific.
A meta-analysis revealed that $20 \mu \mathrm{g}$ of desmopressin reduced nocturia episodes by $0.5-1.5$ per night and increased uninterrupted sleep by an average of two hours. ${ }^{23}$ Although $\beta 3$ agonists were shown to be effective in OAB patients, ${ }^{24}$ data on NDO and especially MS populations are scant. Ongoing studies are currently evaluating them alone and in combination with anticholinergics in these patients. Some promising results have come from cannabis-based extracts and phosphodiesterase inhibitors. Preliminary clinical trials have demonstrated favourable outcomes of these treatments on muscle spasticity ${ }^{25}$ and storage symptoms. ${ }^{26,27}$

\section{Treatment of voiding symptoms}

Alpha-blockers are first-line pharmacological treatments (Level of evidence: 1B) ${ }^{13}$ aimed at reducing bladder outlet resistance in NDO patients. Abrams et el evaluated tamsulosin efficacy in 263 patients with neurogenic lower urinary tract dysfunction secondary to supra-sacral spinal cord lesions. ${ }^{28}$ Four-week, placebo-controlled treatment produced no statistically significant diminution of its primary endpoint maximal urethral pressure. However, a one-year, open-label extension study disclosed increased mean voided volume (based on micturition diary) and improved QOL, as assessed by the International Prostate Symptom Score questionnaire (IPSS) and the severity of autonomic dysreflexia symptoms. Data of its use in MS patients are sparse, especially in women. However, many European consensuses ${ }^{12,14,15}$ still recommend it for voiding symptoms, mainly in men with suspected contribution of benign prostatic obstruction.

Pharmacological treatment of failure to empty (detrusor sphincter dyssynergia [DSD] and/or detrusor underactivity [DU]) remains a significant problem with insufficient remedy. No major breakthroughs have occurred in the field in the last 20 years. In patients with adequate manual dexterity, the most reasonable approach, to decrease the rate and frequency of involunid.y detrusor contractions, would include initiation of IC. ${ }^{29,30}$ Unfortunately, no class of pharmacological agents can selectively relax the external urinary sphincter. Several drugs, including benzodiazepines, dantrolene, baclofen, and $\alpha$-adrenergic antagonists, have been given to treat external sphincter dyssynergia (DESD). ${ }^{31,32}$ Baclofen and diazepam exert their actions predominantly within the central nervous system (CNS), whereas dantrolene directly impacts skeletal muscles. Although these drugs are capable of providing variable relief of muscle spasticity, their efficacy is far from complete. Troublesome adverse events, especially muscle weakness and severe fatigue, mainly in younger patients, minimize their overall utility. Some promising results have arisen from cannabis-based extracts. Preliminary clinical trials have demonstrated the favourable effects of these treatments on muscle spasticity ${ }^{25}$ and storage symptoms. ${ }^{26}$ 
Aharony et al.

Botulinum toxin (BT)

\section{Intrasphincteric BT injection}

Data on BT for the treatment of DESD are very limited. A systemic review found only a small number of articles with mixed patient populations, different injection methods, volume, and dosage. ${ }^{33}$ Gallien et al failed to confirm the significant effectiveness of botulinum toxin A (BoNTA) 100 units over placebo via transperineal injections in the first trial conducted on MS patients. ${ }^{34}$ The short, transient effect, with the need for repeated injections every 3-4 months, are all contributing to the limitation of BT in this situation.

\section{Intradetrusor BT injections}

Since its introduction in the treatment of spinal cord injury (SCl) patients, ${ }^{35}$ data on BT in NDO cases are accumulating. Today, intradetrusor BoNTA injection is considered to be the most effective, minimally-invasive treatment to reduce NDO (Grade A recommendation)..$^{13}$ Several multicentre, randomized, double-blind, placebo-controlled studies, all with very similar methodologies, have determined that BoNTA curbs the UUI rate, improves maximal cystometric capacity (MCC), and enhances urinary-related QOL. ${ }^{36-39}$

In a multicentre, double-blind study, 275 NDO patients (154 with MS) were randomized to placebo vs. intradetrusor BoNTA injection. ${ }^{37} \mathrm{UUI}$ events/week, QOL (measured by the Incontinence Quality of Life questionnaire), MCC, and maximum detrusor pressure at involuntary detrusor contraction (IDC) were all significantly improved.

Herschorn et al followed 57 NDO patients (19 with MS) randomized to placebo or BoNTA 200 or 300 units, in a prospective, double-blind, multicentre study. ${ }^{38}$ Mean daily UUI, Health-related QOL questionnaire scores, and treatment satisfaction improved in comparison to placebo-treated patients, with no clinically relevant differences between BoNTA doses.
BoNTA injection duration was estimated to be 42 weeks ${ }^{37}$ which necessitated repeated injections. Tested in two small cohorts of MS patients, ${ }^{40,41}$ repeated injections delivered around $56 \%$ improvement, with up to $76 \%$ complete continence. Both studies demonstrated a significant decline of patients returning for repeated injections without providing any explanation for this phenomenon.

Another common finding from the above studies, ${ }^{37,38,40,41}$ was that the toxin's effect was dose-dependent, and doseescalation from 200 to 300 units resulted in a higher degree of de novo need for IC without significant clinical improvement. These results standardized treatment to 200 units for NDO management.

In general, MS patients differed greatly from $\mathrm{SCl}$ patients, with the majority still preserving their ability to void. ${ }^{37}$ Initiation of IC could have serious implications for patients' daily lives and should be addressed while offering this treatment to patients who are still urinating by themselves. In these cases, patients should be evaluated for their ability to perform self-catheterizations and informed about the risk of becoming temporarily IC-dependent. However, Gamé et al showed that IC initiation had no negative impact on QOL.42 Mehnert et al tried to address the risk of de novo IC in a case study by reducing BoNTA injection dosage to 100 units. ${ }^{43}$ They noted similar improvement in MCC and lowered maximal detrusor pressure, with about $33 \%$ reduction of de novo need for IC. Table 1 summarizes studies of de novo IC and BoNTA dose levels.

\section{Second- and third-line non-pharmacological options}

\section{Neuromodulation}

Neuromodulation is another option after conservative treatment failure.

\begin{tabular}{|c|c|c|c|c|c|}
\hline & Number of patients & BoNTA dosage & IC-free pre-BoNTA & De novo IC & Indications for IC \\
\hline Kalsi et al ${ }^{40}$ & 43 (MS only) & 300 units $(n=43)$ & $13 / 43(30 \%)$ & $12 / 13(92 \%)$ & $\begin{array}{c}\text { Symptoms \& PVR } \\
\geq 100 \mathrm{cc}\end{array}$ \\
\hline Khan et $\mathrm{al}^{41}$ & 137 (MS only) & 300 units $(n=137)$ & $46 / 137$ (34\%) & $41 / 43(95 \%)$ & $\begin{array}{c}\text { Symptoms \& PVR } \\
\geq 100 \mathrm{cc}\end{array}$ \\
\hline Herschorn et $\mathrm{al}^{38}$ & $57(19 \mathrm{MS})^{*}$ & $\begin{array}{c}\text { Placebo }(n=8) \\
300 \text { units }(n=11)\end{array}$ & $\begin{array}{l}\text { Placebo } 9 / 28(32 \%) \\
300 \text { units } 9 / 27(33 \%)\end{array}$ & $\begin{array}{l}\text { Placebo 2/9 (22\%) } \\
300 \text { units 5/9 (56\%) }\end{array}$ & $N / A^{* *}$ \\
\hline Cruz et al ${ }^{37}$ & 275 (154 MS) & $\begin{array}{l}\text { Placebo }(n=50) \\
200 \text { units }(n=53) \\
300 \text { units }(n=51)\end{array}$ & $\begin{array}{l}\text { Placebo } 39 / 50(78 \%) \\
200 \text { units } 39 / 53(74 \%) \\
300 \text { units } 42 / 51(82 \%)\end{array}$ & $\begin{array}{c}\text { Placebo } 2 / 39(5 \%) \\
200 \text { units } 16 / 39(41 \%) \\
300 \text { units } 27 / 42(64 \%)\end{array}$ & Clinical judgment \\
\hline Mehnert et $\mathrm{al}^{43}$ & 12 (MS only) & 100 units $(n=12)$ & $12 / 12(100 \%)$ & $3 / 12(25 \%)$ & Clinical judgment \\
\hline
\end{tabular}

*No specific data available for the MS subgroup; **not applicable. BoNTA: botulinum toxin A; IC: intermittent catheterization; MS: multiple sclerosis; PVR: post-void residual. 


\section{Sacral neuromodulation (SNM)}

Ever since the U.S. Food and Drug Administration (FDA) approved SNM for refractory UUI in 1997, data on its efficacy in NDO patients have been accumulating. ${ }^{44,45}$ In MS patients, neuromodulation manages storage problems and pelvic floor/sphincter overactivity. The data on MS patients are limited to case series, with mixed treatment indications. This lack of sufficient evidence has prevented its inclusion in expert panel consensus recommendations.

Marinkovic and Gillen determined that 12 of 14 patients were free of the need for IC after SNM, ${ }^{46}$ while Minardi and Muzzonigro saw a trend towards decreasing number of catheterizations per day after SNM. ${ }^{47}$ Given the fact that MS is a changing neurological condition, ongoing magnetic resonance imaging may be needed, but may limit the deployment of chronic metallic implants. Non-implantable neuromodulation would be preferable in such populations.

\section{Transcutaneous posterior tibial nerve stimulation (PTNS)}

PTNS has been shown to improve storage symptoms in two recent studies ${ }^{48,49}$ The patient population differed, to some extent, from the CNS study, as only $13 \%$ were on $\mathrm{IC}^{48}$ and DSD was an exclusion criterion. ${ }^{49}$

\section{Intermittent catheterization}

Self- or third-party IC is the preferred management strategy for NDO patients with related bladder-emptying dysfunction. In order to perform IC, patients must have enough manual dexterity to hold the catheter and expose the urethral meatus. Other pre-IC necessities are sufficient sight, cognition, and body position (a matter of equilibrium and general motor function). Many international consensuses advise on the utility of IC in MS, ${ }^{4,11}$ but no strong evidence supports these recommendations, which include the use of 12-16 Fr catheters, 4-6 times per day, with bladder volume at catheterization limited to 400-500 cc.

Few European consensuses ${ }^{4,14,15}$ have recommended IC initiation whenever PVR exceeds 100-150 cc. However, not all MS patients will benefit from a rigid PVR cutoff for initiation of IC (100-150 cC). IC should not be initiated hastily, as it is not complication-free. Clinical judgment is preferred on rigid cutoffs and should be based on patient age, gender, type and duration of MS, Extended Disability Status Scale (EDSS) scores, symptoms, and ability to perform IC. Other important information includes several PVR measurements, patient symptoms (recurrent UTIs, cystolithiasis, incontinence, etc), and risk of UUT deterioration and bladder capacity, as evaluated by urodynamic study (UDS) or voiding diary.

\section{Indwelling urinary drainage}

When IC-dependent patients cannot catheterize themselves or are unwilling to do so, indwelling catheters are an option.

Suprapubic catheters (SPCs) are preferred over urethral catheters (UCs) for permanent drainage. ${ }^{50,51}$ SPCs avoid known UC complications, such as anterior urethral damage (iatrogenic hypospadias), urethral stricture, fistula formation, epididymitis, and scrotal abscess in men. ${ }^{52}$ In women with $\mathrm{SCl}$, UCs have been shown to cause urethral stricture or erosion in $37.2 \%$ of patients. ${ }^{53}$ SPCs seem especially relevant in MS patients with impaired urethral or perineal sensation who are wheelchair-bound. They eliminate the risk of urethral injury or iatrogenic hypospadias from excessive tension/sitting on catheter tubing. However, SPCs and UCs have similar rates of UUT damage, vesicoureteral reflux, renal or bladder calculi, and symptomatic UTIs. ${ }^{54}$

\section{Third-line treatment alternatives}

Failure of conservative and second-line therapies to correct intractable storage symptoms is becoming less frequent in MS patients. Together with the relatively low risk of renal function deterioration, surgical management of bladder dysfunction has a limited role. However, some patients, especially those who are in a stable disease course with long life expectancy, may benefit from surgery. The options include bladder augmentation, as well as continent and noncontinent urinary diversion. Although the literature on these techniques is extensive, it is unusual for MS patients to be singled out for separate results analysis.

Women with MS may suffer from stress urinary incontinence (SUI) just like neurologically intact women. Therefore, careful evaluation (including cystoscopy and urodynamic testing) is essential to exclude other possible MS-related findings (cystolithiasis, DU, DSD, recurrent UTIs, etc). Several PVR volume measurements should be obtained as well, and the risk of postoperative retention should be assessed. Only then, should a midurethral sling be offered to patients.

\section{Summary of treatment and levels of evidence}

In general, levels of evidence regarding treatment of LUTS in MS are limited. While some data on NDO patients may enable us to achieve Grade A recommendations (based on Level 1-2 evidence studies ${ }^{55}$ ), most of those concerning MS patients are derived from expert consensuses (Level of evidence: 5, Grade D recommendations). If not indicated otherwise in the text, recommendations are all Grade D.

Table 2 summarizes treatment options for different MS-related urinary symptoms. 
Aharony et al.

\begin{tabular}{|c|c|c|c|c|c|}
\hline & & NDO & ND0 \& DSD & NDO \& DU & DU \\
\hline \multirow{2}{*}{$\begin{array}{l}\text { First-line } \\
\text { treatment }\end{array}$} & $\begin{array}{l}\text { Behavioural/ } \\
\text { physical* }\end{array}$ & PFMT & PFMT + biofeedback & Double-voiding & Double-voiding \\
\hline & Pharmacological & Anticholinergics & Baclofen/ $\alpha$-blockers & Anticholinergics** & \\
\hline \multirow{3}{*}{$\begin{array}{l}\text { Second-line } \\
\text { treatment }\end{array}$} & $\begin{array}{l}\text { Botulinum toxin } \\
\text { injection }\end{array}$ & $\begin{array}{l}\text { Intra-detrusor: refractory } \\
\text { NDO and/or risk of UUT } \\
\text { deterioration }\end{array}$ & $\begin{array}{l}\text { Intra-sphincteric: } \\
\text { refractory DSD and/or } \\
\text { Symptomatic high PVR }\end{array}$ & For catheter bypass & \\
\hline & Neuromodulation & Refractory NDO & Refractory NDO & & \\
\hline & $\begin{array}{l}\text { CIC/indwelling } \\
\text { catheters }\end{array}$ & $\begin{array}{l}\text { Refractory NDO and/or risk } \\
\text { of UUT deterioration }\end{array}$ & $\begin{array}{l}\text { Refractory NDO/DSD and/or } \\
\text { risk of UUT deterioration } \\
\text { Symptomatic high PVR }\end{array}$ & $\begin{array}{l}\text { Refractory NDO and/or } \\
\text { risk of UUT deterioration } \\
\text { Symptomatic high PVR }\end{array}$ & $\begin{array}{l}\text { CIC/indwelling } \\
\text { catheter }\end{array}$ \\
\hline $\begin{array}{l}\text { Third-line } \\
\text { treatment }\end{array}$ & $\begin{array}{c}\text { Other/ } \\
\text { experimental }\end{array}$ & Bladder augmentation & Bladder augmentation & $\begin{array}{c}\text { Bladder augmentation, } \\
\text { diversion }\end{array}$ & Diversion \\
\hline
\end{tabular}

\section{Conclusion}

MS is a unique neurological disease with a broad spectrum of urological presentations. Urologists play a major role in the evaluation and treatment of these patients. Thorough knowledge of the disease process is needed to choose the right evaluation tool and the right management option for specific subjects. LUTS evaluation and management in MS patients is intended to identify those who are at risk for UUT deterioration and/or QOL impairment. Anticholinergics, with or without IC, are the mainstay of treating $O A B$ symptoms. When conservative therapy fails to reduce the risk of UUT deterioration or improve patient symptoms because of limited efficacy or adverse events profile, second-line therapy is necessary. The introduction of BoNTA intravesical injection has revolutionized treatment in refractory cases. Further research in this specific population is needed to evaluate the real effects of anticholinergic agents, BT, and SNM.

Competing interests: Dr. Corcos has been an advisor for Allergan, Astellas, and Pfizer; a speaker for Allergan and Duchesnay; has received payment and honoraria from Astellas; and has participated in clinical trials for Allergan and Ipsen. The remaining authors report no competing personal or financial interests.

This paper has been peer-reviewed.

\section{References}

1. Aharony S, Lam 0, Lapierre Y, et al. Multiple sclerosis (MS) for the urologist: What should urologists know about MS? Neurourol Urodyn 2016;35:174-9. https://doi.org/10.1002/nau.22713

2. de Sèze $M$, Ruffion $A$, Denys $P$, et al. The neurogenic bladder in multiple sclerosis: Review of the literature and proposal of management guidelines. Mult Scler 2007;13:915-28. https://doi.org/10.1177/1352458506075651

3. Koldewin $\mathrm{EL}$, Hommes OR, Lemmens WA, et al. Relationship between lower urinary tract abnormalities and disease-related parameters in multiple sclerosis. J Urol 1995;154:169-73. htrps://doi.org/10.1016/ S0022-5347(01)67258-6
4. Fowler $C$, Panicker J, Drake $M$, et al. A UK consensus on the management of the bladder in multiple sclerosis. J Neurol Neurosurg Psychiatry 2009;80:470-7. https://doi.org/10.1136/innp.2008.159178

5. Amaro IL, Gameiro MO, Padovani CR. Effect of intravaginal electrical stimulation on pelvic floor muscle strength. Int Urogynecol J 2005;16: 355-8. https://doi.org/10.1007/s00192-004-1259-0

6. De Ridder D, Vermeulen C, Ketelaer $\mathrm{P}$, et al. Pelvic floor rehabilitation in multiple sclerosis. Acta Neurol Belg1999;99: 61.

7. Lúcio $\mathrm{AC}$, Campos RM, Perissinotto MC, et al. Pelvic floor muscle training in the treatment of lower urinary tract dysfunction in women with multiple sclerosis. Neurourol Urodyn 2010; 29:1410-3. https://doi.org/10.1002/nau.20941

8. McClurg D, Ashe R, Lowe-Strong A. Neuromuscular electrical stimulation and the treatment of lower urinary tract dysfunction in multiple sclerosis—a double blind, placebo-controlled, randomized clinical trial. Neurourol Urodyn 2008;27:231-7. https://doi.org/10.1002/nau.20486

9. McClurg D, Ashe R, Marshall K, et al. Comparison of pelvic floor muscle training, electromyography biofeedback, and neuromuscular electrical stimulation for bladder dysfunction in people with multiple sclerosis: A randomized pilot study. Neurourol Urodyn 2006;25:337-48. https://doi.org/10.1002/nau.20209

10. Litwiller SE, Frohman EM, Zimmern PE. Multiple sclerosis and the urologist. J Urol 1999;161:743-57. https://doi.org/10.1016/S0022-5347(01)61760-9

11. Stöhrer M, Blok B, Castro-Diaz D, et al. EAU guidelines on neurogenic lower urinary tract dysfunction. Eur Urol 2009:56:81-8. https://doi.org/10.1016/i.eururo.2009.04.028

12. Amarenco $G$, Chartier-Kastler $E$, Denys $P$, et al. First-line urological evaluation in multiple sclerosis: Validation of a specific decision-making algorithm. Mult Scler 2013;19:1931-7. hitps://doi.org/10.1177/1352458513489758

13. Groen J, Pannek J, Castro Diaz D, et al. Summary of European Association of Urology (EAU) guidelines on neuro-urology. Eur Urol 2016;69:324-33. htrps://doi.org/10.1016/i.eururo.2015.07.071

14. De Ridder D, Van der Aa F, Debruyne J, et al. Consensus guidelines on the neurologist's role in the management of neurogenic lower urinary tract dysfunction in multiple sclerosis. Clin Neurol Neurosurg 2013;115:2033-40. https://doi.org/10.1016/j.clineuro.2013.06.018

15. Ghezzi A, Carone R, Del Popolo G, et al. Recommendations for the management of urinary disorders in multiple sclerosis: A consensus of the Italian Multiple Sclerosis Study Group. Neurol Sci 201 1;32:1223-31. https://doi.org/10.1007/s10072-011-0794-y

16. Nicholas RS, Friede T, Hollis $\mathrm{S}$, et al. Anticholinergics for urinary symptoms in multiple sclerosis. Cochrane Database Syst Rev 2009 Jan 21:CD004193. https://doi.org/10.1002/14651858.cd004193.pub2

17. Ethans $K$, Nance $P, B$ Bard R, et al. Efficacy and safety of tolterodine in people with neurogenic detrusor overactivity. J Spinal Cord Med 2004;27:214-8. https://doi.org/10.1080/10790268.2004.11753751

18. van Rey F, Heesakkers J. Solifenacin in multiple sclerosis patients with overactive bladder: A prospective study. Adv Urol 2011; 2011:834753

19. Bennett $N, O^{\prime}$ Leary $M$, Patel $A S$, et al. Can higher doses of oxybutynin improve efficacy in neurogenic bladder? J Urol 2004;171:749-51. https://doi.org/10.1097/01.ju.0000103274.38694.b1

20. Todorova A, Vonderheid-Guth B, Dimpfel W. Effects of tolterodine, trospium chloride, and oxybutynin on the central nervous system. J Clin Pharmacol 2001;41:636-44. https://doi.org/10.1177/00912700122010528

21. Sand PK, Dmochowski RR, Reddy J, et al. Efficacy and safety of low-dose desmopressin orally disintegrating tablet in women with nocturia: Results of a multicentre, randomized, double-blind, placebo-controlled, parallel-group study. J Urol 2013;190:958-64. https://doi.org/10.1016/i.juro.2013.02.037 
22. Weiss JP, Zinner NR, Klein BM, et al. Desmopressin orally disintegrating tablet effectively reduces nocturia: Results of a randomized, double-blind, placebo-controlled trial. Neurourol Urodyn 2012;31:441-7. https://doi.org/10.1002/nau.22243

23. Bosma R, Wynia K, Havlikova E, et al. Efficacy of desmopressin in patients with multiple sclerosis suffering from bladder dysfunction: A meta-analysis. Acta Neurol Scand 2005;112:1-5. https://doi.org/10.1111/i.1600-0404.2005.00431.x

24. Herschorn S, Barkin J, Castro-Diaz D, et al. A phase 2, randomized, double-blind, parallel-group, placebocontrolled, multicentre study to assess the efficacy and safety of the 3 adrenoceptor agonist, mirabegron, in patients with symptoms of overactive bladder. Urology 2013;82:313-20. https://doi.org/10.1016/i. urology.2013.02.077

25. Collin C, Davies P, Mutiboko I, et al. Randomized, controlled trial of cannabis-based medicine in spasticity caused by multiple sclerosis. Eur J Neurol 2007;14:290-6. https://doi.org/10.1111/j.14681331.2006.01639.x

26. Brady C, DasGupta R, Dalton C, et al. An open-label pilot study of cannabis-based extracts for bladder dysfunction in advanced multiple sclerosis. Mult Scler 2004;10:425-33. https://doi.org/10.1191/1352458504ms10630a

27. Kanai A, Zabbarova I, Oefelein $M$, et al. Mechanisms of action of botulinum neurotoxins, 3-adrenergic receptor agonists, and PDE5 inhibitors in modulating detrusor function in overactive bladders: ICI-RS 2011. Neurourol Urodyn 2012;31:300-8. https://doi.org/10.1002/nau.21246

28. Abrams $P$, Amarenco $G$, Bakke $A$, et al. Tamsulosin: Efficacy and safety in patients with neurogenic lower urinary tract dysfunction due to suprasacral spinal cord injury. J Urol 2003; 170:1242-51. https://doi.org/10.1097/01.ju.0000084623.65480.f8

29. Lapides J, Diokno A, Silber $S$, et al. Clean, intermittent self-catheterization in the treatment of urinary tract disease. Trans Am Assoc Genitourin Surg 1971;63:92-6.

30. Maynard F, Diokno A. Clean intermittent catheterization for spinal cord injury patients. J Urology 1982; 128:477-80.

31. Hacken H, Krucker V. Clinical and laboratory assessment of the efficacy of baclofen on urethral sphincter spasticity in patients with traumatic paraplegia. Eur Urol 1977;3:237-40.

32. Hackler $\mathrm{R}$, Broecker $\mathrm{B}$, Klein $\mathrm{F}$, et al. A clinical experience with dantrolene sodium for external urinary sphincter hypertonicity in spinal cord injured patients. J Urol 1980;124:78-81.

33. Mangera A, Andersson K-E, Apostolidis A, et al. Contemporary management of lower urinary tract disease with botulinum toxin A: A systematic review of botox (onabotulinumtoxinA) and dysport (abobotulinumtoxinA). Eur Urol 2011;60:784-95. https://doi.org/10.1016/i.eururo.2011.07.001

34. Gallien P, Reymann J, Amarenco G, et al. Placebo-controlled, randomized, double-blind study of the effects of botulinum A toxin on detrusor sphincter dyssynergia in multiple sclerosis patients. J Neurol Neurosurg Psychiatry 2005;76:1670-6. https://doi.org/10.1136/innp.2004.045765

35. Schurch B, Stöhrer M, Kramer G, et al. Botulinum-A toxin for treating detrusor hyperreflexia in spinal cord injured patients: A new alternative to anticholinergic drugs? Preliminary results. J Urology 2000;164:6927. https://doi.org/10.1016/S0022-5347(05)67283-7

36. Chancellor MB, Patel V, Leng WW, et al. OnabotulinumtoxinA improves quality of life in patients with neurogenic detrusor overactivity. Neurology 2013;81:841-8. https://doi.org/10.1212/ WNL.0b013e3182a2ca4d

37. Cruz F, Herschorn S, Aliotta $P$, et al. Efficacy and safety of onabotulinumtoxinA in patients with urinary incontinence due to neurogenic detrusor overactivity: A randomized, double-blind, placebo-controlled trial. Eur Urol 2011;60:742-50. htrps://doi.org/10.1016/i.eururo.2011.07.002

38. Herschorn S, Gajewski J, Ethans K, et al. Efficacy of botulinum toxin A injection for neurogenic detrusor overactivity and urinary incontinence: A randomized, double-blind trial. J Urology 2011;185:2229-35. https://doi.org/10.1016/i.juro.2011.02.004
39. Sussman D, Patel V, Del Popolo G, et al. Treatment satisfaction and improvement in health-related quality of life with onabotulinumtoxinA in patients with urinary incontinence due to neurogenic detrusor overactivity. Neurourol Urodyn 2012;32:242-9. https://doi.org/10.1002/nau.22293

40. Kalsi V, Gonzales $G$, Popat R, et al. Botulinum injections for the treatment of bladder symptoms of multiple sclerosis. Ann Neurol 2007;62:452-7. https://doi.org/10.1002/ana.21209

41. Khan S, Game X, Kalsi V, et al. Long-term effect on quality of life of repeat detrusor injections of botulinum neurotoxin-A for detrusor overactivity in patients with multiple sclerosis. J Urol 2011;185:1344-9. https://doi.org/10.1016/i.juro.2010.12.002

42. Gamé $X$, Castel-Lacanal E, Bentaleb $Y$, et al. Botulinum toxin A detrusor injections in patients with neurogenic detrusor overactivity significantly decrease the incidence of symptomatic urinary tract infections. Eur Urol 2008;53:613-9. https://doi.org/10.1016/i.eururo.2007.08.039

43. Mehnert U, Birzele J, Reuter $\mathrm{K}$, et al. The effect of botulinum toxin type a on overactive bladder symptoms in patients with multiple sclerosis: A pilot study. J Urol 2010;184:1011-6. https://doi.org/10.1016/i. juro.2010.05.035

44. Peters KM, Kandagatla $\mathrm{P}$, Killinger KA, et al. Clinical outcomes of sacral neuromodulation in patients with neurologic conditions. Urology 2013; 81:738-44. htrps://doi.org/10.1016/i.urology.2012.11.073

45. Wallace PA, Lane FL, Noblett KL. Sacral nerve neuromodulation in patients with underlying neurologic disease. Am J Obstet Gynecol 2007;197:96. el-e5.

46. Marinkovic SP, Gillen LM. Sacral neuromodulation for multiple sclerosis patients with urinary retention and clean intermittent catheterization. Int Urogynecol J 2010;21:223-8. https://doi.org/10.1007/ s00192-009-1023-6

47. Minardi D, Muzzonigro G. Sacral neuromodulation in patients with multiple sclerosis. World I Urol 2012;30:123-8. https://doi.org/10.1007/s00345-011-0669-0

48. de Sèze $M$, Raibaut $P$, Gallien $P$, et al. Transcutaneous posterior tibial nerve stimulation for treatment of the overactive bladder syndrome in multiple sclerosis: Results of a multicentre prospective study. Neurourol Urodyn 2011;30:306-11. https://doi.org/10.1002/nau.20958

49. Kabay SC, Yucel M, Kabay S. Acute effect of posterior tibial nerve stimulation on neurogenic detrusor overactivity in patients with multiple sclerosis: Urodynamic study. Urology 2008;71:641-5. https://doi.org/10.1016/i.urology.2007.11.135

50. Mitsui T, Minami K, Furuno T, et al. Is suprapubic cystostomy an optimal urinary management in high quadriplegics? A comparative study of suprapubic cystostomy and clean intermittent catheterization. Eur Urol 2000;38:434-8. https://doi.org/10.1159/000020320

51. Larsen LD, Chamberlin DA, Khonsari F, et al. Retrospective analysis of urologic complications in male patients with spinal cord injury managed with and without indwelling urinary catheters. Urology 1997;50:418-22. https://doi.org/10.1016/S0090-4295(97)00224-0

52. Hunter KF, Bharmal A, Moore KN. Long-term bladder drainage: Suprapubic catheter vs. other methods: A scoping review. Neurourol Urodyn 2013;32:944-51. htrps://doi.org/10.1002/nau.22356

53. Hollingsworth JM, Rogers MA, Krein SL, et al. Determining the non-infectious complications of indwelling urethral catheters: A systematic review and meta-analysis. Ann Intern Med 2013;159:401-10. https://doi.org/10.7326/0003-4819-159-6-201309170-00006

54. Weld KJ, Dmochowski RR. Effect of bladder management on urological complications in spinal cord injured patients. J Urol 2000;163:768-72. htrps://doi.org/10.1016/S0022-5347(05)67800-7

55. Howick J, Chalmers I, Glasziou P, et al. The Oxford 2011 levels of evidence. Oxford Centre for EvidenceBased Medicine 2011. http://www.cebm.net/wp-content/uploads/2014/06/CEBM-Levels-ofEvidence-2.1.pdf. Accessed February 7, 2017.

Correspondence: Dr. Shachar Moshe Aharony, Urology Service, Rabin Medical Centre, Beilinson Hospital, Pteach-Tiqva, Israel; shaharony@gmail.com 